\title{
TROPICAL ACNE - ONE HUNDRED CASES
}

\author{
CAPT JENNIFER M WELLS, MB, ChB, RAMC \\ Regimental Medical Officer, 1 Bn KOSB
}

SUMMARY: One hundred and five cases of Tropical Acne were noted in a battalion after a six-month Belize tour. The anatomical areas affected, and their relationship to climate and treatment are described.

\section{Introduction}

An Infantry Battalion returned to the United Kingdom (UK) from a sixmonth tour in Belize, Central America, in the month of August. In mid-September after a period of leave, nine soldiers presented with acneic skin lesions, all of a similar pattern. A local Consultant Dermatologist saw all nine patients and arranged biopsy of the two typical cases reported below.

As six out of the nine patients affected had noted the lesions only on return to the UK, the entire Battalion was inspected at a co-incidental influenza immunization parade. A total of 105 affected individuals were seen. Severity varied but none was as severely affected as the nine already seen. Lesions varied from small red papules on the shoulders alone, to pustules, papules and comedones on the back and shoulders extending over the upper arms and the lower face. Table I indicates areas affected and the time-scale of development. Although there was no direct correlation between the area affected and the duration of the lesions the mild cases, with lesions over back and shoulders, or shoulders only, had developed in the four weeks preceding the inspection.

\section{Case 1}

\section{Case reports}

Two weeks after return from Belize he noted spots on his back and shoulders. There was no previous history of acne. Lesions consisted of comedones, red dome-shaped papules and pustules on the back and pre-sternal area extending on to the upper arms and chin. The biopsy report indicated:-

Gross: A $4 \times 2 \mathrm{~mm}$ disc of skin, all embedded, and

Microscopic: Histology of three separate levels of skin biopsy showing no abnormality.

\section{Case 2}

This patient noted skin lesions developing after four months in Belize. Again there was no previous history. The lesions were those of cystic acne covering the area from the back of the neck, over the back to above the waist. Milia were present on the face and chest. The biopsy report showed:-

Gross: A disc of skin $6 \times 3 \mathrm{~mm}$, bisected and all embedded, and

Microscopy: Histology showed a non-specific dermal abscess with epithelial lining. The overlying epithelium showing reactive change with multiple small intra-epidermal vescicles. 


\section{Treatment}

Treatment for the nine cases was oxytetracycline $250 \mathrm{mg}$, twice daily, (erythromycin $250 \mathrm{mg}$ being used for those resistent to oxytetracycline), and Panoxyl-5 Gel, topically.

Treatment for the 105 additional patients commenced as recommended. Cases with mild papules alone were not given Panoxyl-5, and Eskamel Acne Ointment was substituted. All cases except the mildest were treated with oxytetracycline $250 \mathrm{mg}$ bd orally for one month initially. Abscesses were incised as they developed. Swabs taken in such cases showed no growth.

\section{Results}

Most mild cases cleared after four weeks treatment; those on whom lesions persisted responded to a further course of treatment. Severe cases took longer to respond, some up to five months, and three cases are still (eight months later) under survey. For these three the lesions include still-active papules, a few pustules, and several comedones; scarring has been extensive but is noted to have faded with time. The original treatment is still in use and this, together with mild scrubbing with a soft nail-brush and a simple soap, is achieving good results.

One of the original nine cases has now left the Army, but has been confirmed as a case of Acne aestivalis. This patient had been previously unaffected by acne, but after six months treatment still has several active papules and pustules with considerable scarring on the back and pre-sternal area.

\section{Discussion}

The main purpose of this article is to document those cases with no previous acne history, that is 83 per cent of the total. From Table $I$ it is obvious that the chance of developing the lesions is directly proportional to time spent in the climate. Temperatures averaged around $32^{\circ} \mathrm{C}$ with relative humidity rising to 90 per cent and over in the latter part of the tour during the rainy season. Whether a tour from August to February - the drier season - would produce the same result is open to question.

Table I

Tropical acne, time scales of development of lesions, and areas affected

\begin{tabular}{cclc}
\hline $\begin{array}{c}\text { Time Iesions } \\
\text { present (month) }\end{array}$ & $\begin{array}{c}\text { Percentage } \\
\text { affected }\end{array}$ & \multicolumn{1}{c}{ Area affected } & $\begin{array}{c}\text { Percentage } \\
\text { patients }\end{array}$ \\
\hline 1 & 46 & Back and shoulders & 35 \\
2 & 17 & Face and back & 24 \\
3 & 11 & Back only & 23 \\
4 & 6 & Shoulders only & 9 \\
5 & 2 & Face, back and chest & 9 \\
$\begin{array}{c}\text { More than } 6 \\
\text { (previously } \\
\text { affected) }\end{array}$ & 17 & & \\
\hline
\end{tabular}


It is noteworthy that one Company in the Battalion produced only four cases of mild acne (three per cent), as compared with the overall 19 per cent affected. This group spent the last eight weeks of the tour in an area of Belize which was fresher in climate and less humid than the rest of the country, although the temperature was as high elsewhere. These four cases developed only on return to UK. The case of Acne aestivalis however, had spent almost the entire tour on a Cay, or small island on the coast where temperatures were high but humidity much lower with sea breezes.

Seventeen per cent of the total 105 had previously suffered from mild Acne vulgaris. No firm percentages are available, but some of these soldiers noted an improvement in their acne in Belize, and a relapse on return. Those in very humid parts of the country suffered recurrences whilst in Belize.

The eruptions described above do not resemble Acne vulgaris. Typically the first lesion to appear was the red papule, as seen on the shoulders of mild cases, and this did not seem related to the comedone which later appeared in the more severe cases but seemed to develop as the result, rather than the cause, of the skin changes and build-up of debris. The distribution too was atypical, affecting shoulders and upper arms. Swabs of abscesses and pustules yielded no growth, unlike vulgaris.

The climate was obviously in some way responsible. Ultraviolet (PUVA) rays have been noted $^{1}$ to produce an acne-form eruption when used to treat psoriasis, and in this case humidity was postulated as a co-factor. Acne aestivalis, or 'Majorca $A c n e^{2}$ is now well accepted as a direct result of exposure to sunlight, but the histological features in the two cases quoted here do not conform to its accepted pattern. In a further case of Acne aestivalis ${ }^{3}$ sunbathing was regarded as entirely co-incidental, because lesions developed even when sunlight was deliberately avoided. In that case sweating was associated with the lesions and occlusive adhesive taping exacerbated the condition.

Many of the 46 per cent who developed acneic spots in the first four weeks after return to the UK claimed to have noted the first appearance of lesions either on the flight home, or within the first few days of arrival. There may have been some connection with the wearing of shirts and an increase in sweating because soldiers spent a lot of time in 'bare buff' whilst in the tropics.

High levels of humidity would seem to have been an important bearing on the matter, as some immunity was enjoyed by those stationed in less humid areas, even though these soldiers had to spend time in the jungle where the humidity was high. It is suggested that sunlight alone cannot be held responsible.

In Cases 1, 2 and 3 quoted above, tetracyclines were found to be ineffective; in the present report most of the numbers responded to courses of oxytetracycline.

The causation of "Tropical Acne" therefore remains a puzzle. Although in the cases studied only a small percentage sought treatment because of severity, 
and in the remainder the condition seemed to be self-limited, it must still be considered one of the hazards of service in hot and humid climates.

\section{Acknowledgement}

I am grateful to Dr D I McCallum, Consultant Dermatologist of Raigmore Hospital, Inverness, for all his advice, and for arranging biopsies and photographs.

\section{REFERENCES}

1. Jones, C and BLEeHAN, S S (1971). Br Med J ii, 866.

2. HJORTH, N et al (1972). Acta Derm Venereol (Stockh) 52, 61.

3. Mills, O H and Kligman, A M (1975). Arch Dermatol 111, 891.

\section{Director of Army General Practice}

The Director General Army Medical Services and the Army Establishment Committee have agreed, that the post of Adviser in General Practice in the Rank of Colonel is to be replaced by a Director of Army General Practice, in the Rank of Brigadier, with effect from 1 June 1980.

\section{Honorary Consultant}

Professor J P Watson, MD, FRCP, FRCPsych, has been appointed Honorary Consultant in Psychiatry to the Army, with effect from 12 October 1980. He succeeds Dr D Leigh, MD, FRCP, who has retired. 